\title{
A STUDY OF COMORBIDITY BETWEEN OPIOID ADDICTION AND MAJOR DEPRESSIVE DISORDERS IN EL HUSSEIN UNIVERSITY HOSPITAL
}

\author{
By \\ Mohammad Mostafa Abd Allah, Mohammad Hashem Bahary, \\ Mohammed El-Sayed Mohamed Ramadan and Mohammed Ahmed \\ Abou-zaid \\ Psychiatry Department, Faculty of Medicine, Al-Azhar University, Cairo, Egypt \\ *Corresponding Author: Abd Allah, Mohammad Mostafa, \\ E-mail: psychiatry137@gmail.com
}

\begin{abstract}
Background: Comorbidity of substance abuse and mental disorders is a major issue in psychiatry that notably associates with more severe symptoms, longer illness duration, and higher service utilization. Therefore, identifying key clusters of comorbidity represent important steps toward improving mental health care.

Objective: To assess the relationship between opioid addiction and the comorbidity of major depressive disorders, explore the characteristics of patients using different types of opioids, and assessment of the severity of addiction and depression.

Patients and Methods: The sample consisted of 229 patients diagnosed with opioid use disorder according to DSM -IV, and their ages ranged from 15-50 years old. They were subjected to a semi-structured interview sheet, a structured clinical interview for DSM-IV (SCID-I) to diagnose psychiatric disorders, the addiction severity index scale, urine drug screening, and Hamilton depression scale.

Results: The most common psychiatric comorbidity was major depressive disorder representing $32.8 \%$ of the total sample. Patients with comorbid major depressive disorder had statistically significant higher history of suicidal attempt, history of overdose, number of treatment trials, and previous admission for addiction problems as compared with patients with no comorbidity. The prevalence of MDD comorbidity was $55 \%$ among tramadol users, $26.2 \%$ in heroin users, and $18.8 \%$ in Nalbuphine users.
\end{abstract}

Conclusion: There was a significant relation between opioids addiction and major depressive disorder, between the severity of addiction and psychiatric comorbidity.

Keywords: Opioid abuse, Comorbidity, Depression.

\section{INTRODUCTION}

According to Bewley-Taylor and Nougier (2018), 53 million people worldwide had used opioids in the previous year; these estimates are 56\% higher than the previous estimated. Opioid dependence involves a cluster of symptoms, including impaired control over use, prominence of use of a substance in a person's life, and physiological symptoms such as tolerance and withdrawal. Major depressive 
disorder (MDD) is one of the most prevalent mental disorders worldwide, as well as one of the most disabling. According to the global burden of disease study, depression is the fourth leading cause of disability and it is expected to be the second by 2020 (Gutiérrez-Rojas et $a l ., 2020)$. Opioid dependence, have more than four times the expected risk of mortality, with life expectancies reduced by more than nine years compared to national norms (Hayes et al., 2011).

A 2016 study in the Annals of family medicine found that about $10 \%$ of people prescribed opioids developed after a month of taking drugs. The longer they use opioids, the greater risk of developing depression become (Scherrer et al., 2016). The relationship between opioids and depression is close, complex, and multifaceted; depression is associated with endogenous opioid dysfunction and depression associated with opioid abuse (Sullivan, 2018). Patients with major depressive disorder who experienced social rejection shows reduced endogenous opioid release in the brain regions that regulate mood and motivation and show slower emotional recovery compared to healthy controls (Hsu et al., 2015).

The present work aimed to assess the relationship between opioid addiction and the comorbidity of major depressive disorders, explore the characteristics of patients using different types of opioids, and assessment of the severity of addiction and depression.

\section{PATIENTS AND METHODS}

This study was a cross-sectional study using a convenience sample of patients diagnosed with opioid dependency. All patients were selected from the outpatient clinic and inpatient department at psychiatry and addiction unit at AlHussein university hospital. Selected patients were fulfilling the diagnosis of opioid dependency according to DSM-IV. The time frame of the study was between March 2017 and September 2018.

Inclusion criteria: Age: $15-50$ years, both sexes, and patients fulfilling the diagnosis of opioid addiction according to DSM-IV.

Exclusion criteria for the patients: Patients using opioids for medical indication and under medical supervision (e.g. cancer), and patients with belowaverage intelligence (e.g. Mental retardation).

The requirements of Al-Azhar University Ethics Committee were fulfilled, and informed oral consent has been obtained from every patient before participating in the study. Using a semistructured interview, starting with socio demographic characteristics of the patients, family history and substance use pattern, type, onset, reason, relation to symptoms severity or relief, relapse rates, and treatment trials if any.

\section{Structured Clinical Interview for DSM-}

IV (SCID I): The semi-structured diagnostic interview begins with a section on demographic information and clinical background. Then, there were 7 diagnostic modules, focused on different diagnostic groups: mood, psychotic, substance abuse, anxiety, somatoform, eating, and adjustment disorders. It was considered the standard interview to verify the diagnosis in clinical trials and was extensively used in other forms of psychiatric research. Hamilton Depression 
Scale (HAM-D) scale was used for the assessment of depressive status as each of the nine DSM IV items has a score in the test. This scale was used for patients with the diagnosis of major depressive disorder. The 17 points scale was used with the following cut-off points: 0-11 for minor or no depression (mild), 12-18 for less than major depression (moderate), 1924 for major depression (severe), and 25 or =more for severe depression (very severe). The Addiction severity index (ASI) version 5 was based on a structured interview that provides extensive information on substance use and psychosocial functioning in seven domains: medical, employment, alcohol abuse, drug abuse, legal, family/social and psychological. ASI was a reliable valid tool for the assessment of drug use and has shown excellent capabilities for characterizing severe addiction problems with multiple areas of dysfunction. Urine screening for drugs to confirm the diagnosis, urine drug screening was done for tramadol HCL, opioids, benzodiazepines, and cannabinoids.

\section{Statistical analysis:}

Demographic characteristics, psychiatric assessment and addiction history of the patients is summarized using the mean, standard deviation, median and quartiles for numeric data and frequency distribution for categorical data. Comparison of categorical data between patients with major depressive disorder and patients without co-morbidity was done using chi-square test and Fisher's exact test, while comparison of numerical data was done using independent t-test and Mann Whitney U test. All analyses were done using SPSS version 26 (USA). A p-value of 0.05 or less was considered significant.

\section{RESULTS}

The study sample consisted of 229 patients who were opioid-addicted. $61.1 \%$ of them were interviewed at outpatient settings while the others were inpatients. Female patients were only 32 representing $14 \%$ of the study group. The highest prevalence of MDD comorbidity was observed among tramadol users (55.0\%), followed by heroin $(26.2 \%)$, and the least was in Nalbuphine users (18.8\%). The mean age was $28.2(\mathrm{SD}=8.6)$ years. $47.6 \%$ of the patients were living in rural areas, while $52.4 \%$ were living in urban areas. Patients had different levels of education: Non-educated were $18.3 \%$, those with primary education were $30.1 \%$, secondary education were $29.3 \%$, while those with university degree were $22.3 \%$. The employment status was: unemployed $14.4 \%$, worker $25.8 \%$, student $21.0 \%$, employee $18.8 \%$, business owner $15.3 \%$ and housewives $4.8 \%$. $45.4 \%$ of the participants said that they had an irregular occupation in the last 3 years and $44.1 \%$ said that they are receiving financial support from their families. Almost half of the participants were single $48.5 \%$, the married patients are $38.0 \%$, and the divorced are $10.9 \%$ while the widows are $2.8 \%$. The highest percentages of participants $(56.8 \%)$ are from the middle social class, $21.8 \%$ are from the high class and $21.4 \%$ are from the low class. There was a positive family history for psychiatric disorders in $37.1 \%$ of patients and a positive family history of substance abuse in $41.5 \%$ of them. $56 \%$ of the patients have psychiatric co-morbidities (Figure 1). 


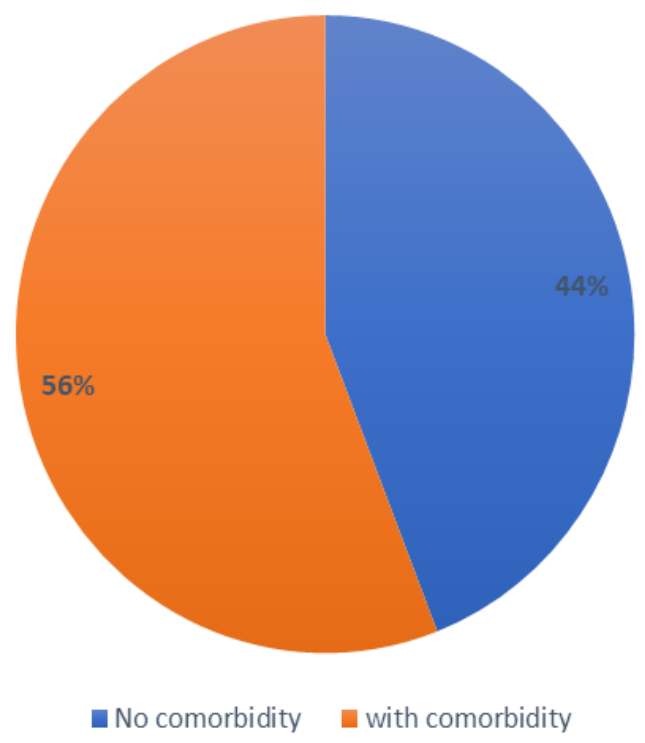

Figure (1): Prevalence of psychiatric co-morbidities among opioid addicts

The most common psychiatric comorbidity was the major depressive disorder, found in 75 patients representing $32.8 \%$ of the total sample, followed by anxiety disorder in $7 \%$ of patients. Other comorbidities were found at lower frequencies (Figure 2).

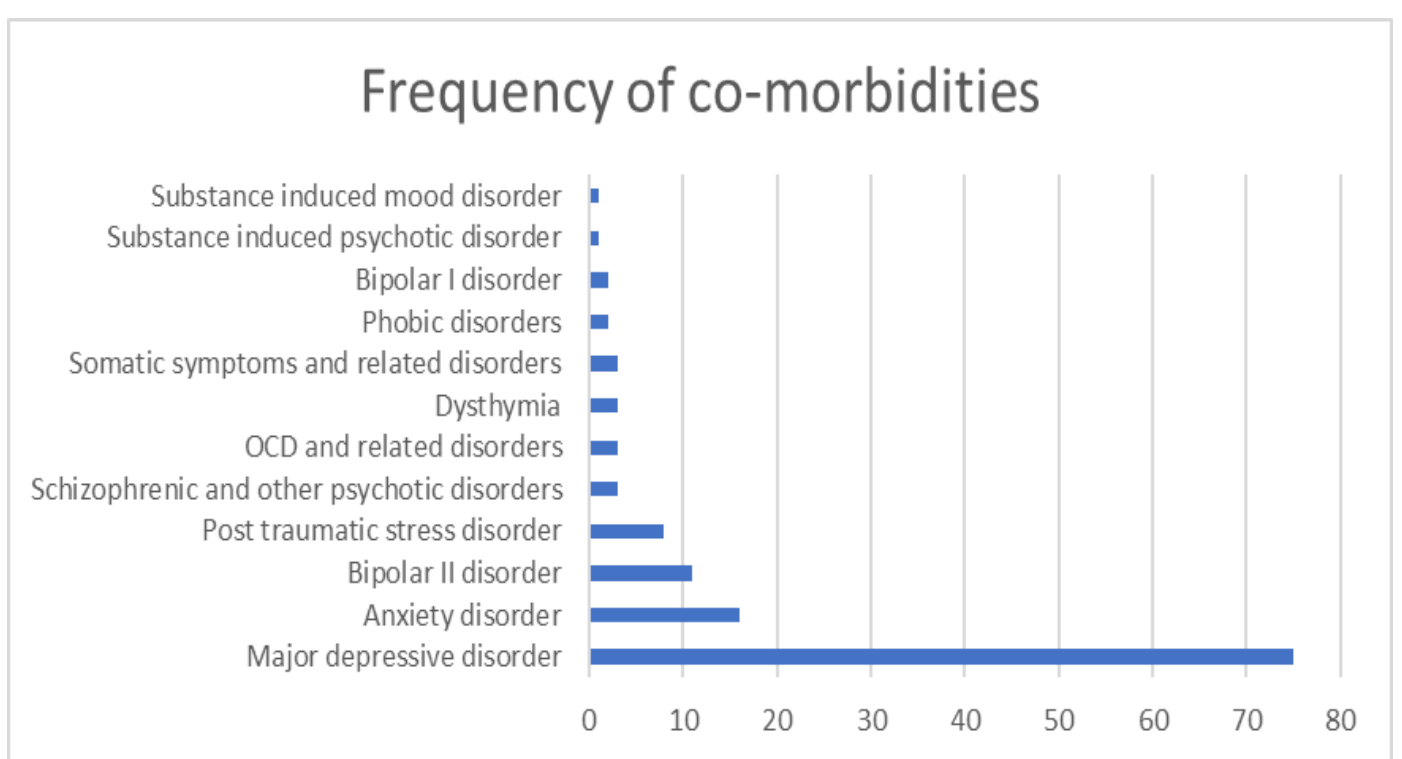

Figure (2): Psychiatric co-morbidities distribution in the sample

The addiction severity index was assessed in all patients and was given a score from 1 to 5 according to severity. In the medical, employment family and social aspects the most frequent category was moderate followed by mild with few cases in the extreme category. For the psychiatric aspect, the most common category was the severe $44.5 \%$, and for the legal aspect, most cases $(66.8 \%)$ had no legal consequences (Table 1). 
Table (1): Scores for the addiction severity index of the patients

\begin{tabular}{|c|c|c|c|c|c|c|c|}
\hline $\begin{array}{c}\text { Addiction } \\
\text { severity } \\
\text { index }\end{array}$ & $\begin{array}{c}\text { Medical } \\
\text { N }(\%)\end{array}$ & $\begin{array}{c}\text { Employment } \\
\text { N (\%) }\end{array}$ & $\begin{array}{c}\text { Drug } \\
\text { N }(\%)\end{array}$ & $\begin{array}{c}\text { Family } \\
\text { N }(\%)\end{array}$ & $\begin{array}{c}\text { Social } \\
\text { N }(\%)\end{array}$ & $\begin{array}{c}\text { Psychiatric } \\
\text { N }(\%)\end{array}$ & $\begin{array}{c}\text { Legal } \\
\text { N }(\%)\end{array}$ \\
\hline No & $44(19.2)$ & $38(16.6)$ & $19(8.3)$ & $30(13.1)$ & $38(16.6)$ & $21(9.2)$ & $153(66.8)$ \\
\hline Mild & $55(24.0)$ & $46(20.1)$ & $51(22.3)$ & $45(19.7)$ & $46(20.1)$ & $34(14.8)$ & $21(9.2)$ \\
\hline Moderate & $69(30.1)$ & $84(36.7)$ & $83(36.2)$ & $90(39.3)$ & $87(38.0)$ & $58(25.3)$ & $34(14.8)$ \\
\hline Severe & $57(24.9)$ & $53(23.1)$ & $63(27.5)$ & $57(24.9)$ & $52(22.7)$ & $102(44.5)$ & $19(8.3)$ \\
\hline Extreme & $4(1.7)$ & $8(3.5)$ & $13(5.7)$ & $7(3.1)$ & $6(2.6)$ & $14(6.1)$ & $2(0.9)$ \\
\hline
\end{tabular}

Comparison of the sociodemographic factors between patients with major depressive disorder and patients with no co-morbidity showed that the only significant difference was observed in the educational level $\mathbf{x}$ A higher percentage of patients with MDD (35\%) are not educated as compared to the percentage of those who are not educated in patients with no co-morbidity (9\%). (Figure 2).

Table (2): Comparison of patients with MDD versus of opioid addicts with no comorbidity in Sociodemographic characteristics

\begin{tabular}{|c|c|c|c|c|c|}
\hline \multicolumn{2}{|l|}{ Parameters } & $\begin{array}{c}\text { No comorbidity } \\
\mathrm{N}=101\end{array}$ & $\begin{array}{l}\text { MDD } \\
\mathrm{N}=75\end{array}$ & Total & P-value \\
\hline \multirow{2}{*}{ Sex } & Male & $91(90.1)$ & $61(81.3)$ & $152(86.4)$ & \multirow{2}{*}{0.094} \\
\hline & Female & $10(9.9)$ & $14(18.7)$ & $24(13.6)$ & \\
\hline \multirow{2}{*}{ Residence } & Rural & $47(46.5)$ & $37(49.3)$ & $84(47.7)$ & \multirow{2}{*}{0.713} \\
\hline & Urban & $54(53.5)$ & $38(50.7)$ & $92(52.3)$ & \\
\hline \multirow{4}{*}{ Education } & Not educated & $9(8.9)$ & $26(34.7)$ & 35 (19.9) & \multirow{4}{*}{$<0.001$} \\
\hline & primary & $32(31.7)$ & $16(21.3)$ & $48(27.3)$ & \\
\hline & secondary & $35(34.7)$ & $18(24.0)$ & $53(30.1)$ & \\
\hline & university & $25(24.8)$ & $15(20.0)$ & $40(22.7)$ & \\
\hline \multirow{6}{*}{ Employment } & unemployed & $10(9.9 \%)$ & $13(17.3)$ & $23(13.1)$ & \multirow{6}{*}{0.564} \\
\hline & worker & $28(27.7)$ & $17(22.7)$ & $45(25.6)$ & \\
\hline & student & $20(19.8)$ & $17(22.7)$ & $37(21.0)$ & \\
\hline & employee & $24(23.8)$ & $12(16.0)$ & $36(20.5)$ & \\
\hline & business owner & $15(14.9)$ & $12(16.0)$ & $27(15.3)$ & \\
\hline & house wife & $4(4.0)$ & $4(5.3)$ & $8(4.5)$ & \\
\hline \multirow{2}{*}{$\begin{array}{c}\text { Occupation in last } \\
3 \text { years } \\
\end{array}$} & regular & $62(61.4)$ & $37(49.3)$ & $99(56.3)$ & \multirow{2}{*}{0.111} \\
\hline & irregular & $39(38.6)$ & $38(50.7)$ & $77(43.8)$ & \\
\hline \multirow{2}{*}{$\begin{array}{c}\text { Family support } \\
\text { patient financially }\end{array}$} & Yes & $51(50.5)$ & $33(44.0)$ & $84(47.7)$ & \multirow{2}{*}{0.394} \\
\hline & No & $50(49.5)$ & $42(56.0)$ & $92(52.3)$ & \\
\hline \multirow{4}{*}{ Marital status } & Single & $49(48.5)$ & $34(45.3)$ & $83(47.2)$ & \multirow{4}{*}{0.058} \\
\hline & Married & $42(41.6)$ & $23(30.7)$ & $65(36.9)$ & \\
\hline & Divorced & $9(8.9)$ & $14(18.7)$ & $23(13.1)$ & \\
\hline & Widow & $1(1.0)$ & $4(5.3)$ & $5(2.8)$ & \\
\hline \multirow{3}{*}{ Social class } & Low & $17(16.8)$ & $20(26.7)$ & $37(21.0)$ & \multirow{3}{*}{0.188} \\
\hline & middle & $64(63.4)$ & $38(50.7)$ & $102(58.0)$ & \\
\hline & High & $20(19.8)$ & $17(22.7)$ & $37(21.0)$ & \\
\hline \multirow{2}{*}{$\begin{array}{c}\text { Family history of } \\
\text { psychiatric } \\
\text { disorder }\end{array}$} & No & $65(64.4)$ & $47(62.7)$ & $112(63.6)$ & \multirow[b]{2}{*}{0.818} \\
\hline & Yes & $36(35.6)$ & $28(37.3)$ & $64(36.4)$ & \\
\hline \multirow{2}{*}{$\begin{array}{c}\text { Family history of } \\
\text { SUD }\end{array}$} & No & $57(57)$ & $43(57)$ & $100(57)$ & \multirow{2}{*}{0.905} \\
\hline & Yes & $44(44)$ & $32(43)$ & $76(43)$ & \\
\hline
\end{tabular}


There was no difference between the two groups regarding age, age of onset or duration of addiction. The difference was observed in number of treatment trials without abstinence, abstinence more than one month, previous admission for addiction problems, suicidal attempt and history of over dose. Patients with MDD had higher numbers and significant statistical differences in these items A higher percentage of patients with MDD comorbidity had a history of suicidal attempts, $36 \%$ versus $12 \%$ in the group with no co-morbidity. A higher percentage of patients with MDD comorbidity had a history of overdose, $43 \%$ versus $28 \%$ in the group with no co-morbidity. (Table 3).

Table (3): Comparison of patients with MDD versus of opioid addicts with no comorbidity in clinical data

\begin{tabular}{|c|c|c|c|c|c|}
\hline & & $\mathbf{N}$ & Mean & SD & P-value \\
\hline \multirow{2}{*}{ Age } & No comorbidity & 101 & 27.9 & 8.8 & \multirow{2}{*}{0.622} \\
\hline & MDD & 74 & 28.6 & 8.4 & \\
\hline \multirow{2}{*}{ Age of onset } & No comorbidity & 101 & 22.9 & 7.9 & \multirow{2}{*}{0.475} \\
\hline & MDD & 74 & 22.1 & 6 & \\
\hline \multirow{2}{*}{ Duration } & No comorbidity & 101 & 4.1 & 2.3 & \multirow{2}{*}{0.2} \\
\hline & MDD & 74 & 4.7 & 3.7 & \\
\hline \multirow{2}{*}{$\begin{array}{c}\text { Number of treatment } \\
\text { trials without } \\
\text { abstinence }\end{array}$} & No comorbidity & 101 & 1.6 & 1.5 & \multirow[b]{2}{*}{$<0.001$} \\
\hline & MDD & 74 & 2.6 & 1.9 & \\
\hline \multirow{2}{*}{$\begin{array}{l}\text { Abstinence more than } \\
\text { one month }\end{array}$} & No comorbidity & 101 & 0.6 & 0.7 & \multirow{2}{*}{$<0.001$} \\
\hline & MDD & 74 & 1.1 & 0.8 & \\
\hline \multirow{2}{*}{$\begin{array}{l}\text { Previous admission for } \\
\text { addiction problems }\end{array}$} & No comorbidity & 101 & 0.3 & 0.6 & \multirow{2}{*}{$<0.001$} \\
\hline & MDD & 74 & 0.9 & 0.9 & \\
\hline \multirow{2}{*}{ Suicidal attempts } & No comorbidity, $\mathrm{N}(\%)$ & \multicolumn{3}{|c|}{$12(12)$} & \multirow{2}{*}{0.001} \\
\hline & $\mathrm{MDD}, \mathrm{N}(\%)$ & & $27(36$ & & \\
\hline \multirow{2}{*}{ History of overdose } & No comorbidity, $\mathrm{N}(\%)$ & & $28(28$ & & \\
\hline & $\mathrm{MDD}, \mathrm{N}(\%)$ & & $32(43$ & & \\
\hline
\end{tabular}

Comparison of ASI between MDD and no co-morbidity groups was done using Mann Whitney U test as shown in table 4. The only ASI component that showed a significant difference between the two groups is the psychiatric component which is more severe in the MDD group (Table 4).

Table (4): Comparison of ASI between patients with MDD and no co-morbidity groups

\begin{tabular}{|c|c|c|c|c|c|c|c|}
\hline & \multicolumn{3}{|c|}{ No comorbidity } & \multicolumn{3}{c|}{ MDD } & \multirow{2}{*}{ P-value } \\
\hline ASI & Median & Q1 & Q3 & Median & Q1 & Q3 & \\
\hline Employment & 3.00 & 2.00 & 3.00 & 3.00 & 2.00 & 4.00 & 0.880 \\
\hline Medical & 3.00 & 2.00 & 3.00 & 3.00 & 2.00 & 4.00 & 0.769 \\
\hline Drug & 3.00 & 2.00 & 4.00 & 3.00 & 2.00 & 4.00 & 0.397 \\
\hline Family & 3.00 & 2.00 & 3.00 & 3.00 & 2.00 & 4.00 & 0.468 \\
\hline Social & 3.00 & 2.00 & 3.00 & 3.00 & 2.00 & 4.00 & 0.274 \\
\hline Psychiatric & 3.00 & 2.00 & 4.00 & 4.00 & 3.00 & 4.00 & $<\mathbf{0 . 0 0 1}$ \\
\hline Legal & 1.00 & 1.00 & 2.00 & 1.00 & 1.00 & 3.00 & 0.053 \\
\hline
\end{tabular}




\section{DISCUSSION}

Clinical and epidemiological studies have revealed a high rate of comorbid psychiatric disorders in opioid-dependent patients including those with prescription opioid dependence (Gros et al., 2013 and Pereiro et al., 2013). The age of our sample was almost similar to the results of other Egyptian studies on substance use, in which the mean age of participants was 30.2 (El-Sheikh et al., 2017), 29.1 (Shahin et al., 2018), and 26-35 years old (Hamdi et al., 2016). $47.6 \%$ of the patients were living in rural areas, while $52.4 \%$ were living in urban areas. Female patients were only $14 \%$ of the study group. This was in agreement with the results of an Egyptian study carried out by El-Sawy et al., (2010) who studied possible gender differences in the ways of first exposure to drugs, the risks of abuse, and the pattern of drug dependence. They found that males start drug abuse earlier in age than females with a longer duration of addiction. The same result was concluded also by the Egyptian National Addiction Survey which showed that substance abuse was more common in males than in females (Hamdi et al., 2011). Both studies related this under-representation to the possibility of lower rates of substance abuse among women in the general population and/or higher barriers to accessing treatment stemming from the social stigma towards substance users, especially women. Patients had different levels of education as non-educated were $18.3 \%$, those with primary education were $30.7 \%$, secondary education $29.8 \%$, while those with a university degree were 23.7\%. This was consistent with Hamdi et al. (2016) that associated substance usage with lower education, as $34.2 \%$ of those who had a primary school education, $25.1 \%$ of illiterate persons, $23.2 \%$ who completed preparatory school education and $22.8 \%$ who can barely read and write were substance users. Our result was inconsistence with Teixidó-Companó et al. (2017) who showed that higher educational level was associated with substance used, $66.1 \%$ of males had secondary education, $20 \%$ of males had a university education, and $13.9 \%$ of males had primary or lower education. This difference may be attributed to the difference in education status in both countries. The employment status was as follows: unemployed $14.4 \%$, worker $25.8 \%$, student $21.0 \%$, employee $18.8 \%$, business owner $15.3 \%$ and housewives $4.8 \%$. $45.4 \%$ of the participants said that they had an irregular occupation in the last 3 years and $44.1 \%$ said that they are receiving financial support from their families .This result was consistent with that of Hamdi et al. (2011) that found substance abuse was more common among those who are manual workers. It was also consistent with the result reached by Abd el Wahab et al., (2018) who found that $53 \%$ of opioid dependents had irregular work history in the past three years, and $45 \%$ received financial help/support from their families. This may be explained by the public attitude towards drug addicts that they are rejected and are not being hired/ employed by work owners (Silverman et al., 2016). A problem that is related to the associated stigma, the doubt of treatment affectivity and policy support, and the functional impairment and performance decline of the addicts in general. Almost half of the participants were single $48.5 \%$, the married patients are $38.0 \%$, the divorced 
are $10.9 \%$ while the widows are $2.8 \%$. This result is consistent with international results as in a survey on hard drug users in Nepal (2010), where close results were observed showing that the percentage of never-married $(64 \%)$, the married $(30 \%)$ and $4.1 \%$ were divorced. The highest percentages of participants $(56.8 \%)$ are from the middle social class, $21.8 \%$ are from high class and $21.4 \%$ are from the low class. The result isn't consistent with other studies (El-Sheikh et al., 2017) that stated that $66.7 \%$ of substance-dependent men were divorced. There was a positive family history for psychiatric disorders in $37.1 \%$ of patients and a positive family history of substance abuse in $41.5 \%$ of them. Those findings are consistent with Asaad et al. (2014) who found that (46\%) of subjects of their sample had a positive family history of substance abuse. The highest percentage of patients in the study group were addicted on tramadol (55.0\%), followed by heroin $(26.2 \%)$ and the least was Nalbuphine addicted by $18.8 \%$ of the sample. These results are supported by the results of The Fund Prevention and Treatment of Addiction and Abuse in Egypt in the first six months in 2013 that showed that Tramadol was at the top of narcotic substances in Egypt.

The most common psychiatric comorbidity in our was the major depressive disorder, found in 75 patients representing $32.8 \%$ of the total sample, followed by anxiety disorder in $7 \%$ of patients It is also consistent with Gross et al. (2013) who found that $47.1 \%$ of opioid dependents were diagnosed with a comorbid mood disorder and also consisted with Sordo et al. (2012) who suggest that the lifetime risk of a comorbid diagnosis with depression can range from $38 \%$ to $56 \%$ amongst those with an opioid addiction. Understanding the bidirectional relationship between opioid addiction and depression and the factors contributing to the comorbidity can provide a critical insight into preventing, diagnosing, and identifying risk factors associated with the development of the disorders. However, factors underlying the overrepresentation of mood disorders among opioid addicts remain unclear (Veilleux et al., 2010). Depressed individuals use opioid to alleviate negative mood (Koob, 2013), and it is the subsequent improvement in mood state that increases the reinforcement value of drug use.

Comparison of ASI between MDD and no co-morbidity groups was done using Mann Whitney U test. The only ASI component that showed significant difference between the two groups is the psychiatric component which is more severe in the MDD group These findings were consistent with the findings reported by other researchers who suggested that SUD would exacerbate depressive disorder, make the subject more withdrawn, more depressed, might lead to increased number of episodes of depression, and at the same time SUD might lead to chronicity of major depressive disorder (MDD) and with Erfan et al. (2010), 93.3\% of comorbid depression and substance use disorder were within the "very severe" and "severe" categories of psychiatric status impairment.

Comparison of the sociodemographic factors between patients with major depressive disorder and patients with no co-morbidity showed that the only 
significant difference was observed in the educational level higher percentage of patients with MDD (35\%) are not educated as compared to the percentage of those who are not educated in the patients with no co-morbidity (9\%). It was consistent with Mohamed et al. (2013) that found in the study dual diagnosis and psychosocial correlates in substance abuse that patients with comorbid substance use disorder and psychiatric disorder had increase percent in illiterates than compared with participants without comorbidity.

The difference was observed in number of treatment trials without abstinence, abstinence more than one month, previous admission for addiction problems, suicidal attempt and history of overdose. Patients with MDD had higher numbers and significant statistical differences in these items. This result is consistent with a lot of studies. Depression increases the risk of relapse after withdrawal (Goesling et al., 2015; Sullivan, 2016; and Feingold et al., 2018), and, simultaneously, the severity and duration of depressive symptoms in MDD are greater if people who suffer from MDD also suffer addiction (Scherrer et al., 2016), and also consisted with Erfan et al. (2010) that found $86 \%$ of his study group with comorbid depression and substance use disorder had suicidal attempt compared to $43.3 \%$ of the control group patients.

\section{CONCLUSION}

The most common psychiatric comorbidity was major depressive disorder representing $32,8 \%$ of total sample. The highest percentages of patients using opioid were addicted on tramadol, followed by heroin, and the least was Nalbuphine addicted. There was a significant relation between the severity of addiction and psychiatric comorbidity.

\section{REFERENCES}

1. AbdelWahab, M. A., Abou el Magd, S. F., Grella, C. E., Enaba, D. A. and Abdel Maqsoud, R. (2018): An examination of motives for tramadol and heroin use in an Egyptian sample. Journal of Addictive Diseases, 37(3-4): 123-134.

2. Asaad, T., Okasha, T., Ramy, H., Fekry, M., Zaki, N., Azzam, H. and Ahmed, S. (2014): Correlates of psychiatric co-morbidity in a sample of Egyptian patients with bipolar disorder. Journal of Affective Disorders, 166: 347-352.

3. Bewley-Taylor, D. R. and Nougier, $M$. (2018): Measuring the 'world drug problem': 2019 and beyond. In Collapse of the Global Order on Drugs: From UNGASS 2016 to Review 2019. Emerald Publishing Limited.

4. El-Sheikh, S. M., Abolmagd, S., Abdelazim, S. and Enaba, D. (2017): The assessment of sexuality and sex hormone levels in a group of synthetic opioid-dependent patients. Middle East current psychiatry, 24(4): 161-167.

5. Erfan, S., Hashim, A. H., Shaheen, M. and Sabry, N. (2010): Effect of comorbid depression on substance use disorders. Substance Abuse, 31(3): 162-169.

6. Feingold, D., Brill, S., Goor-Aryeh, I., Delayahu, Y. and Lev-Ran, S. (2018): The association between severity of depression and prescription opioid misuse among chronic pain patients with and without anxiety: a cross-sectional study. Journal of Affective Disorders, 235: 293-302.

7. Goesling, J., Henry, M. J., Moser, S. E., Rastogi, M., Hassett, A. L., Clauw, D. J. and Brummett, C. M. (2015): Symptoms of depression are associated with opioid use regardless of pain severity and physical functioning among treatment-seeking patients with chronic pain. The Journal of Pain, 16(9): 844-851.

8. Gros, D. F., Milanak, M. E., Brady, K. T. and Back, S. E. J. T. A. (2013): Frequency 
and severity of comorbid mood and anxiety disorders in prescription opioid dependence. The American Journal on Addictions, 22(3): 261-265.

9. Gutiérrez-Rojas, L., Porras-Segovia, A., Dunne, H., Andrade-González, N. and Cervilla, J. A. (2020): Prevalence and correlates of major depressive disorder: a systematic review. Brazilian Journal of Psychiatry, 42(6): 657-672.

10. Hamdi, E., Sabry, N., Sedrac, A. and Refaat, O. (2011): The national addiction survey-final report. Egypt: Research Unit of General Secretariat of Mental Health, Ministry of Health.

11. Hamdi, E., Sabry, N., Sedrak, A., Khowailed, A., Loza, N., Rabie, M. and Ramy, H. J. J. A. P. (2016): Sociodemographic indicators for substance use and abuse in Egypt. 4(1):1- 8.

12. Hayes, R. D., Chang, C. K., Fernandes, A., Broadbent, M., Lee, W., Hotopf, M. and Stewart, R. (2011): Associations between substance use disorder sub-groups, life expectancy and all-cause mortality in a large British specialist mental healthcare service. Drug and Alcohol Dependence, 118(1): 56-61.

13. Hsu, D. T., Sanford, B. J., Meyers, K. K., Love, T. M., Hazlett, K. E., Walker, S. J. and Zubieta, J. K. (2015): It still hurts: altered endogenous opioid activity in the brain during social rejection and acceptance in major depressive disorder. Molecular Psychiatry, 20(2): 193-200.

14. Koob, G. F. (2013): Negative reinforcement in drug addiction: the darkness within. Current Opinion in Neurobiology, 23(4): 559-563.

15. Mohamed, N. R., Hammad, S. A., El Hamrawy, L. G., Rajab, A. Z., El Bahy, M. S. and Soltan, M. R. (2013): Dual diagnosis and psychosocial correlates in substance abuse in Menoufia, Egypt. Menoufia Medical Journal, 26(2):114-121.

16. Pereiro, C., Pino, C., Florez, G., Arrojo, M., Becona, E. and One, C. G. J. P. (2013):
Psychiatric comorbidity in patients from the addictive disorders assistance units of Galicia: The COPSIAD study. PloS One, 8(6), e66451.

17. Scherrer, J. F., Salas, J., Copeland, L. A., Stock, E. M., Ahmedani, B. K., Sullivan, M. D. ... and Lustman, P. J. (2016): Prescription opioid duration, dose, and increased risk of depression in 3 large patient populations. The Annals of Family Medicine, 14(1):54-62.

18. Shahin, M., Fouad, A. A., Saleh, A. A. and Magdy, A. J. E. J. o. P. (2018): Suicide risk and personality traits among Egyptian patients with substance use disorders. Egyptian Journal of Psychiatry, 39(1):15-22.

19. Silverman, K., Holtyn, A. F. and Morrison, R. J. T. i. i. p. s. (2016): The therapeutic utility of employment in treating drug addiction: Science to application. Translational Issues in Psychological Science, 2(2):203-212.

20. Sordo, L., Chahua, M., Bravo, M., Barrio, G., Brugal, M., Domingo-Salvany, A. and Group, I. P. J. A. b. (2012): Depression among regular heroin users: the influence of gender. Addictive behaviors, 37(1): 148-152.

21. Sullivan, M. D. (2016): Why does depression promote long-term opioid use?. Pain, 157(11): 2395-2396.

22. Sullivan, M. D. (2018): Depression effects on long-term prescription opioid use, abuse, and addiction. The Clinical Journal of Pain, 34(9):878-884.

23. Teixidó-Compañó, E., Espelt, A., Sordo, L., Bravo, M. J., Sarasa-Renedo, A., Indave, B. I. and Brugal, M. T. J. G. s. (2018): Differences between men and women in substance use: the role of educational level and employment status. Gaceta Sanitaria, 32: 41-47.

24. Veilleux, J. C., Colvin, P. J., Anderson, J., York, C. and Heinz, A. J. (2010): A review of opioid dependence treatment: pharmacological and psychosocial interventions to treat opioid addiction. Clinical Psychology Review, 30(2):155-166. 


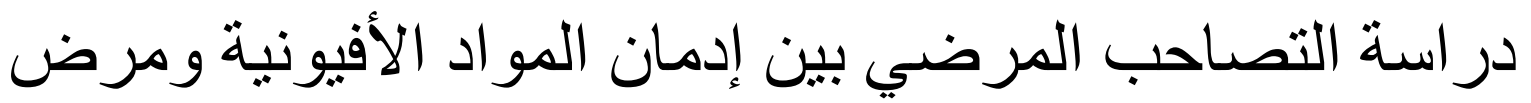

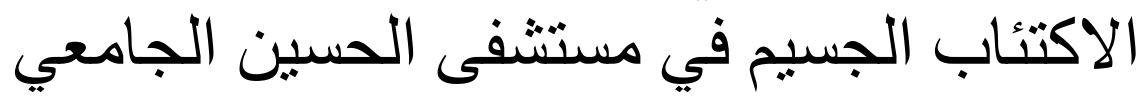

محمد مصطفى عبدالله*،، محمد هاشم بحري، محمد السيد رمضان

$$
\text { قسم الطب النفسي، كلية طب الأزهر }
$$

E-mail: psychiatry137@gmail.com

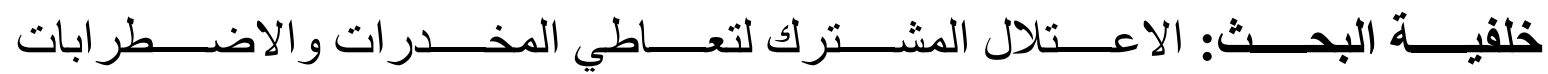

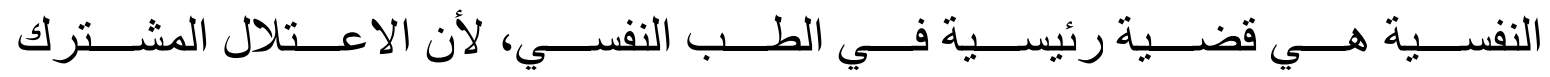

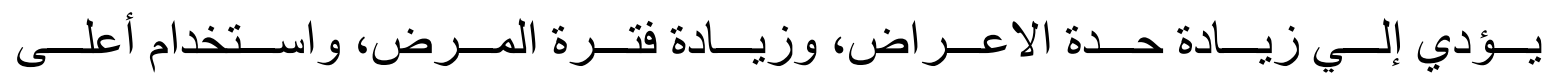

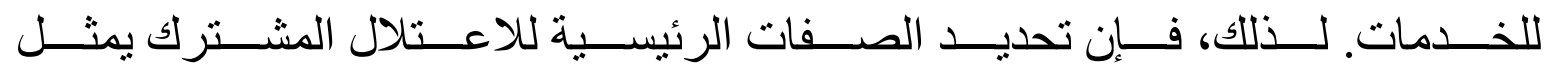
خطوات مهمة نحو تحسين رعاية الصحة النفسية.

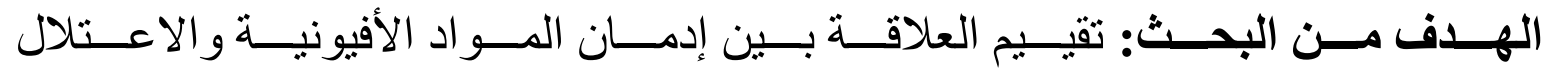

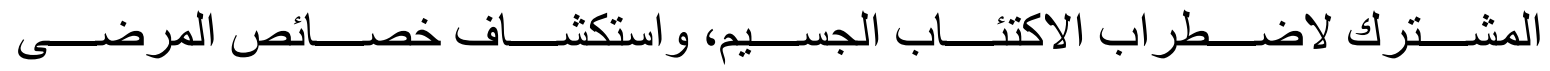

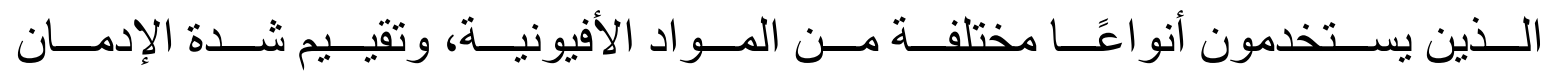

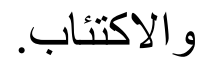

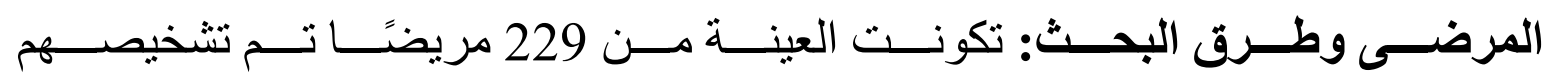

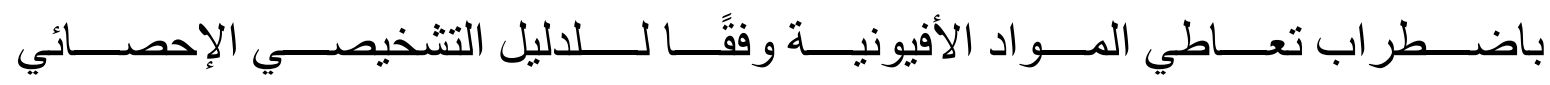

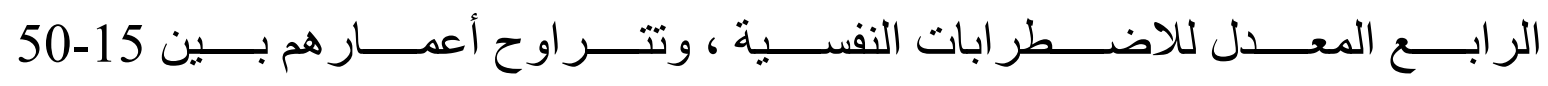

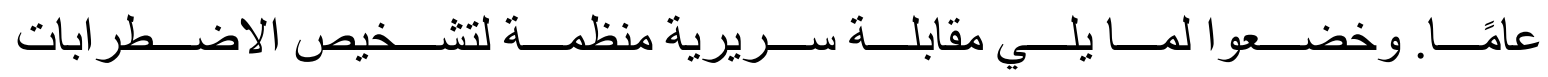

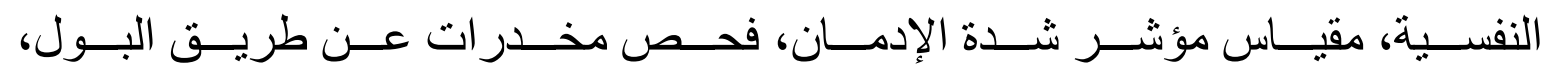
ومقياس هاملتون للاكتئاب.

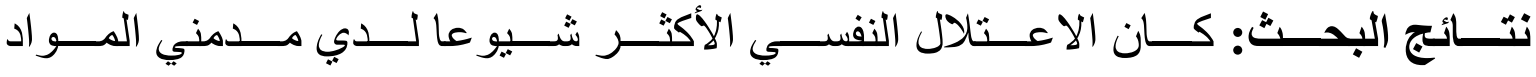

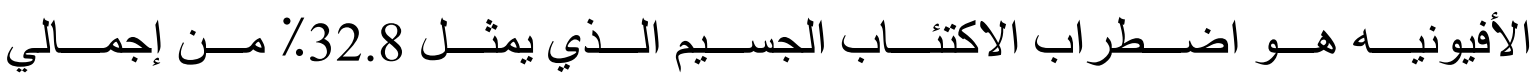

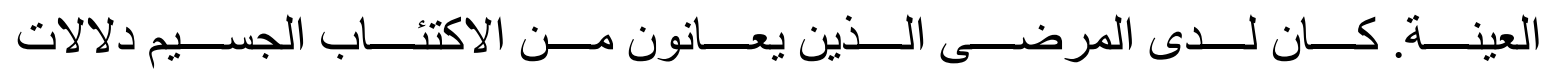




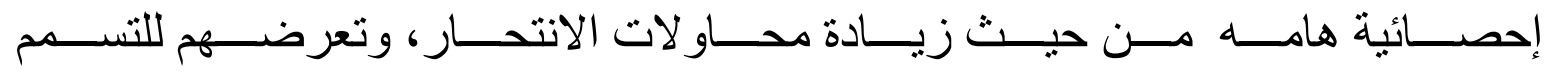

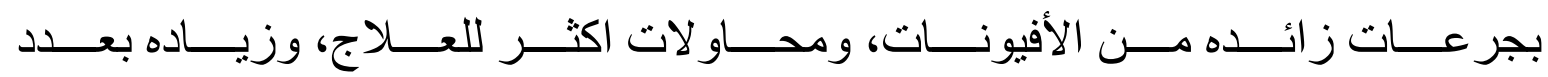

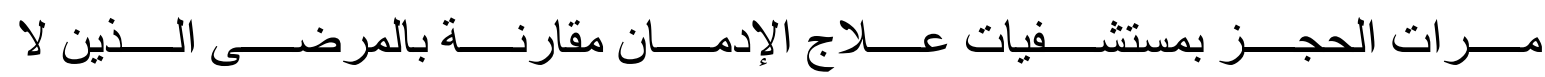
يعانون من اعتلال مشترك.

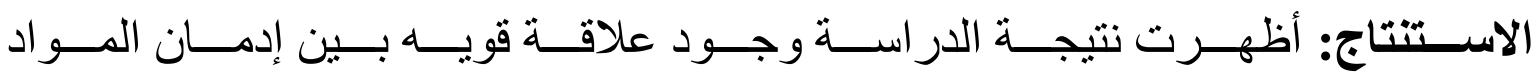
الأفيونية و اضطر اب الاكتئاب الجسيم، بين شدة الإدمان وشدة الاكتئاب. الكلمات الدالة: إدمان المواد الأفيونية، التصاحب المرضي، الاكتئاب. 